\title{
Physical activity evaluation in Yugoslav Study of the Precursors of Atherosclerosis in School Children - YUSAD study
}

Slavko Simeunovic ${ }^{1}$, Zeljka Milincic', Dejan Nikolic ${ }^{2}$, Dejan Simeunovic ${ }^{3}$, Dragana Arandjelovic ${ }^{4}$, Ivana Novakovic ${ }^{1}$, Ivana Petronic'2 Dijana Risimic ${ }^{3}$, Srecko Nedeljkovic', Milija Vukotic ${ }^{1}$

1School of Medicine, University of Belgrade, Belgrade, Serbia

2Physical Medicine and Rehabilitation Department, University Children's Hospital, Belgrade, Serbia

${ }^{3}$ Clinical Center of Serbia, Belgrade, Serbia

4Health Care Facility "Dr Simo Milosevic", Belgrade, Serbia

Submitted: 25 January 2010

Accepted: 25 February 2010

Arch Med Sci 2010; 6, 6: 874-878

DOI: 10.5114/aoms.2010.19294

Copyright @ 2010 Termedia \& Banach

\section{Abstract}

Introduction: It is observed that there is a lack of physical activity and exercise in children, stressing higher prevalence of childhood obesity. The purpose of the study was to evaluate duration of physical activity in a child population and correlation of dynamics in physical activity during 5 years of follow-up in the same population.

Material and methods: We evaluated 3243 school children from 12 regional centres across Serbia. The first examination was done when the children were 10 years old (baseline group), while the second examination was done on the same population when children were 15 years old. Physical activity was classified as recreational activity after school. We analysed 3 groups regarding physical activity: a group of children who were physically active less than 1 hour per day (group I), a second group active from 1 hour to $<3$ hours per day (group II), and a third group active $\geq 3$ hours per day (group III).

Results: In our study we have found on examination that the majority of children were physically active between 1 and 3 hours per day. Our results indicate that there is significant movement from groups I and III toward group II on the second examination regarding the proportion in the baseline group. There is a significant increase in the number of children in group I as they get older.

Conclusions: School children in Serbia are physically active predominantly between 1 and 3 hours per day at the age between 10 and 15 years.

Key words: physical activity, school children, cardiovascular disease

\section{Introduction}

Cardiovascular diseases (CVD) are among the main causes of morbidity and mortality in developed countries as well as in developing countries [1]. Obesity is associated with many cardiovascular risk factors (e.g., lack of physical activity, cholesterol levels and diabetes) [2, 3]. Thus as an appropriate target for primary prevention measures, modification of obesity and introduction of physical activity has the potential to influence certain important clinical conditions that include lipid profile and blood pressure [4].

\author{
Corresponding author: \\ Dejan Nikolic, MD, MSc \\ Physical Medicine and \\ Rehabilitation Department \\ University Children's Hospital \\ Nikole Stefanovica 3 \\ 11000 Belgrade, Serbia \\ Phone: +38 1638133345 \\ E-mail: denikol27@yahoo.com
}


Several studies that have been conducted over the last 40 years have demonstrated strong evidence that atherosclerotic processes occur in early childhood [5]. Furthermore, it is observed that fatty streaks develop during the fetal period and appear in the aortic intima at 3 years of age $[6,7]$.

Lack of physical activity and exercise already exists in children, pointing out higher prevalence of childhood obesity [8]. It has been shown that physical activity primarily affects HDL levels, while some studies demonstrated its positive correlation with LDL levels as well $[9,10]$.

In the presence of multiple risk factors that are connected with atherosclerotic processes there is increased likelihood of CVD occurrence [11]. Therefore, there is a strong need to influence modifiable risk factors in order to reduce the frequency and severity of CVD.

The purpose of the study was to evaluate how many hours children spent during the day in physical activity and to evaluate the correlation of dynamics in physical activity during 5 years of follow-up in the same population as well.

\section{Material and methods}

The Yugoslav Study of the Precursors of Atherosclerosis in School Children (YUSAD) is a prospective multicentric study that began in 1998. The present analysis was limited to 3243 children regarding the physical activity parameter. The first examination was carried out during regular health checkups within primary health care settings when children were 10 years old (baseline group). For the purpose of follow-up, a second examination was done on the same population 5 years later when children were 15 years old.

In the YUSAD study 12 regional centres across Serbia were randomly selected, taking into consideration different social and economic parameters. School children from the Serbian population within these centres were chosen randomly as well, taking into account the population size in evaluated centres in order for the formed cohort of participants to be representative.

Data on age of participants and time spent in physical activity were collected. Physical activity was classified as recreational activity after school. We analysed 3 groups regarding physical activity: a group of children who were physically active less than 1 hour per day (group I), a second group including children with physical activity from 1 hour to $<3$ hours per day (group II), and a third group including children who were physically active $\geq 3$ hours per day (group III).

We evaluated further atherogenic risk factors and their trend during 5 years of follow-up: body mass index (BMI), waist circumference, systolic blood pressure, diastolic blood pressure, glucose plasma levels, low density lipoprotein (LDL) and high density lipoprotein (HDL) cholesterol separately for boys and girls.

\section{Statistical analysis}

The presentation of the distribution and trend of school children in table 1, for every category was described by whole numbers and percentages that express the proportion of children aged 10 years who remained or changed to another group during 5 years. To present the proportion of participants in table 3 , in all 3 groups during the 5 -year period we used percentages.

The values of BMI, waist circumference, blood pressure, glucose plasma, LDL and HDL cholesterol were presented as mean values with standard deviation (SD).

Chi square test was used to compare proportions between two different groups of children 15 years old within every group when children were 10 years old (baseline group). For comparison of the same groups regarding duration of physical activity between school children 10 and 15 years old we used $\chi^{2}$ test. To compare values of risk factors during the 5 -year period we used Student's $t$-test.

\section{Results}

Results of changes in dynamics of physical activity in the evaluated population of school children from the YUSAD study are described in table I. During the 5-year period of follow-up our results stress the significant proportion of children in group II on both the first examination $(87.67 \%$ of children) and the second re-evaluation (80.14\% of children). There was no significant difference in the number of participants within group II over the 5 -year period $\left(X^{2}=0.68 ; p>0.05\right)$ (Table I).

The statistical correlation between groups of physical activity of children 15 years old per each group of physical activity in the baseline group is presented in table II. Our results indicate that there is a significant movement from groups I and III to group II of school children 15 years old for each group of physical activity in the baseline group, while a significant trend of movement from group I to group III and vice versa was observed only for baseline groups I and II (Table II).

Beside the values for baseline at 10 and 15 years old for the entire population, the dynamic of value changes for every category is presented in table III. It is observed that there is a statistically significant increase in the number of children in group I as they get older $(p<0.01)$. A statistically significant decline in the number of children who were physically active more than 1 hour per day was also noticed during the 5-year period of follow-up (Table III). 
Table I. Distribution and trend of children in evaluated groups during five years of follow-up

\begin{tabular}{|lccc|}
\hline \multirow{2}{*}{10 years } & \multicolumn{3}{c|}{15 years } \\
\cline { 2 - 4 } & Group I & Group II & Group III \\
\hline Group I & $7(28.00 \%)$ & $17(68.00 \%)$ & $1(4.00 \%)$ \\
\hline Group II & $403(14.16 \%)$ & $2279(80.61 \%)$ & $161(5.66 \%)$ \\
\hline Group III & $41(10.94 \%)$ & $303(80.80 \%)$ & $31(8.27 \%)$ \\
\hline
\end{tabular}

Table II. Statistical correlation between groups of children age of 15 years for each baseline group of physical activity

\begin{tabular}{|lccc|}
\hline 10 years & \multicolumn{3}{|c|}{$\mathrm{X}^{2}$ ( $p$ values) } \\
\cline { 2 - 4 } & \multicolumn{3}{c|}{15 years } \\
\cline { 2 - 4 } & Group I and II & Group I and III & Group II and III \\
\hline Group I & $40.34^{* *}$ & $82.29^{\star *}$ & $542.12^{* *}$ \\
\hline Group II & $183.31^{\star \star}$ & $8.94^{\star}$ & $531.09^{\star *}$ \\
\hline Group III & $253.25^{\star *}$ & 0.76 & $350.61^{\star *}$ \\
\hline${ }^{*} p<0.01 ;{ }^{* *} p<0.001$ & & \\
\hline
\end{tabular}

Table III. Participants proportions in evaluated groups during five years of follow-up

\begin{tabular}{|lccc|}
\hline \multirow{2}{*}{$\begin{array}{l}\text { Physical } \\
\text { activity groups }\end{array}$} & \multicolumn{2}{c}{ Proportion of participants } & $X^{2}$ ( $p$ value) \\
\cline { 2 - 3 } & 10 years (\%) & 15 years (\%) & \\
\hline Group I & 0.77 & 13.91 & $118.32^{* *}$ \\
\hline Group II & 87.67 & 80.14 & 0.68 \\
\hline Group III & 11.56 & 5.95 & $4.01^{*}$ \\
\hline${ }^{*} p<0.05 ;{ }^{* *} p<0.001$ & & & \\
\hline
\end{tabular}

In table IV we present values of certain risk factors in the evaluated population. There was a significant increase in BMI and waist circumference for both genders during the 5 years $(p<0.01)$. Our study revealed a significant decrease in LDL values $(p<0.01)$ and a significant increase in glucose plasma levels regarding both genders, while a significant increase in HDL values was observed in girls $(p<0.01)$ (Table IV).

Blood pressure values for the evaluated population are presented in table V. During the 5-year period there is a significant increase in both systolic and diastolic blood pressure values $(p<0.001)$ (Table V).

\section{Discussion}

Body size and its composition are under the influence of normal growth. Disruption in the equilibrium of energy intake and energy expenditure can correlate with weight gain that can be maintained during adolescence. Several studies show a significant decline in physical activity in the group of adolescents leading to the development of obesity [12, 13]. Therefore it is of great importance to establish "healthy manners" in adolescents with adequate dynamics of physical activity and sedentary habits.

Lifestyle interventions have great potential and are effective in the prevention of CVD. One among identifiable lifestyle parameters is physical activity. Numerous studies suggest multiple benefits of increased physical activity. By being active, a population tends to increase energy expenditure, improve cardiovascular fitness, decrease intraabdominal fat and establish better glucose control [14-17]. Also there is evidence that exercise increases serum interleukin 6, a cytokine that has an influence on insulin sensitivity and suppression of inflammation [18]. Decreasing central adiposity has a great influence on maintaining normal endothelial function, with reduction of adhesive molecules [19].

The first parameter that we wanted to analyse included the dynamics and change of physical activity duration in every group from baseline over a 5-year period. In our study there was a positive trend for children who were within the first group on the first examination when they were 10 years old. We observed a statistically significant increase ( $p<0.001$ ) of physical activity during the 5 -year period with predominant movement towards being active between 1 and 3 hours per day. Such dynamics bring us to the conclusion that those children with duration of physical activity from group I tend to prolong their activity to a duration of 1 to 3 hours per day rather than being active more than 3 hours per day. On the other hand, among those from group $\mathrm{II}$, the predominant majority remained in the same group, while a negative trend towards spending less time in physical activity was observed to be more frequent

Table IV. Atherosclerosis risk factors values and trends in evaluated population

\begin{tabular}{|lcccc|}
\hline Risk factors values & \multicolumn{2}{c|}{ Boys } & \multicolumn{2}{c|}{ Girls } \\
\cline { 2 - 5 } & 10 years & 15 years & 10 years & 15 years \\
\hline BMI $\left[\mathrm{kg} / \mathrm{m}^{2}\right]$ & $17.16 \pm 2.82$ & $20.30 \pm 3.34^{*}$ & $16.96 \pm 2.91$ & $20.54 \pm 3.41^{*}$ \\
\hline Waist circumference $[\mathrm{cm}]$ & $61.67 \pm 8.10$ & $71.74 \pm 9.18^{*}$ & $61.20 \pm 8.13$ & $70.16 \pm 8.67^{*}$ \\
\hline Sugar plasma levels $[\mathrm{mmol} / \mathrm{l}]$ & $4.82 \pm 0.75$ & $4.91 \pm 0.85^{*}$ & $4.66 \pm 0.74$ & $4.74 \pm 0.78^{*}$ \\
\hline LDL $[\mathrm{mmol} / \mathrm{l}]$ & $2.65 \pm 0.74$ & $2.36 \pm 0.86^{*}$ & $2.74 \pm 0.78$ & $2.51 \pm 0.89^{*}$ \\
\hline HDL $[\mathrm{mmol} / \mathrm{l}]$ & $1.44 \pm 0.35$ & $1.42 \pm 0.44$ & $1.40 \pm 0.35$ & $1.51 \pm 0.48^{*}$ \\
\hline
\end{tabular}

${ }^{*} p<0.001$ 
than a positive trend towards being active more than 3 hours. Children from group III decreased their activity over the 5-year period predominantly for being active for 1 to 3 hours rather than being active less than 1 hour per day.

From our results we can clearly state that whether children were from group I, II or III at baseline, as they get older they tend to be physically active in the range from 1 to 3 hours per day in the age period between 10 and 15 years. Such an observation is a model for healthier lifestyle habits. Being physically active within such a range, especially for this observed population, is far more beneficial than being just active less than 1 hour per day or more than 3 hours. This conclusion implies the postulation that childhood is considered as an important stage for adoption and promotion of regular physical activity patterns during adolescence even later in life [20].

The second parameter that we wanted to analyse and obtain more information about included the proportion of all 3 groups from the baseline evaluation in every group of physical activity when the children turned 15 years. Therefore, our results showed that among those children from group I at 15 years old, a significant proportion (89.36\%) was from those who were physically active between 1 and 3 hours per day when they were 10 years old. Results within this group point to a decrease in duration of physical activity, but such a proportion was expected, since the predominant category of evaluated children was group II at baseline. However, when taking into consideration the population proportion according to every category, after 5 years of follow-up, the greatest proportion was from those who were within group I, while the smallest proportion was from those who were from group III at baseline.

In group II of evaluated children, $80.61 \%$ of those children who were from group II at baseline remained within the same activity module 5 years later. It can be observed that the majority of children from the other two categories during 5 years of follow-up moved to physical activity between 1 and 3 hours per day. In the group of those who were physically active for more than 3 hours per day, only $8.27 \%$ remained in the same mode; the great majority from this group were children who prolonged their physical activity, while only 1 child who was active for less than 1 hour prolonged activity to more than 3 hours per day.

We have demonstrated that there was a significant increase of BMI and waist circumference values for both genders. Such an increase is due to the growth and development in this age group rather than because of increased fat deposits due to inactivity or eating habits. The parameters that justify this opinion are the LDL and HDL values, which
Table V. Blood pressure values in evaluated population

\begin{tabular}{|lcc|}
\hline Blood pressure & \multicolumn{2}{c|}{ School children } \\
\cline { 2 - 3 } & \multicolumn{1}{c|}{10 years } & 15 years \\
\hline $\begin{array}{l}\text { Systolic blood pressure } \\
{[\mathrm{mmHg}]}\end{array}$ & $107.00 \pm 11.04$ & $114.00 \pm 12.02^{*}$ \\
\hline $\begin{array}{l}\text { Diastolic blood pressure } \\
{[\mathrm{mmHg}]}\end{array}$ & $62.00 \pm 10.65$ & $63.00 \pm 12.61^{*}$ \\
\hline
\end{tabular}

${ }^{*} p<0.001$

presented positive trends (decreased atherogenic potential) over the 5-year period, especially in the group of girls. Even though we found a significant increase of blood pressure values, they are in the normal range for the observed age [21].

In our study we have demonstrated that school children in Serbia are physically active predominantly between 1 and 3 hours per day for the age between 10 and 15 years.

This leads to the conclusion that in Serbia there are in general positive tendencies of physical activity duration among school children.

\section{Reference}

1. Laurenti R, Buchalla CM, Carantin CVS. Doença isquêmica do coraçõo: internações, tempo de permanência e gastos. Brasil, 1993 a 1997. Arq Bras Cardiol 2000; 74: 483-7.

2. Disorders of the cardiovascular system. In: Kasper DL, Braunwald E, Fauci AS, et al. (eds.). Harrisons Principles of Internal Medicine. $16^{\text {th }}$ ed. New York: Mc Graw-Hill; 2004.

3. Wilson PW, D'Agostino RB, Sullivan L, Parise H, Kannel WB. Overweight and obesity as determinants of cardiovascular risk: the Framingham experience. Arch Intern Med 2002; 162: 1867-72.

4. Poirier P, Giles TD, Bray GA, et al. Obesity and cardiovascular disease: pathophysiology, evaluation, and effect of weight loss: an update of the 1997 American Heart Association Scientific Statement on Obesity and Heart Disease from the Obesity Committee of the Council on Nutrition, Physical Activity, and Metabolism. Circulation 2006; 113: 898-918.

5. Newman WP III, Freedman DS, Voors AW, et al. Relation of serum lipoprotein levels and systolic blood pressure to early atherosclerosis: the Bogalusa Heart Study. N Engl J Med 1986; 314: 138-44.

6. Napoli C, Glass CK, Witztum JL, Deutsch R, D'Armiento FP, Palinski W. Influence of maternal hypercholesterolemia during pregnancy on progression of early atherosclerotic lesions in childhood: Fate of Early Lesions in Children (FELIC) study. Lancet 1999; 354: 1234-41.

7. Ford ES. C-reactive protein concentration and cardiovascular disease risk factors in children: findings from the National Health and Nutrition Examination Survey 1999-2000. Circulation 2003; 108: 1053-8.

8. Steinbeck KS. The importance of physical activity in the prevention of overweight and obesity in childhood: to review and in opinion. Obes Rev 2001; 2: 117-30.

9. Maron BJ, Chaitman BR, Ackerman MJ, et al. Recommendations for physical activity and recreational sports participation for young patients with genetic cardiovascular diseases. Circulation 2004; 109: 2807-16. 
10. Strong WB, Malina RM, Blimkie CJ, et al. Evidence-based physical activity for school-age youth. J Pediatr 2005; 146: 732-7.

11. Tolfrey K. Intraindividual variability of children's blood, lipid and lipoptotein concentrations: a review. Prev Cardiol 2002; 3: $145-51$.

12. Sallis JF. Age-related decline in physical activity: a synthesis of human and animal studies. Med Sci Sport Exerc 2000; 32: 1598-600.

13. Dietz WH. Critical periods in childhood for the development of obesity. Am J Clin Nutr 1994; 59: 955-9.

14. Frey-Hewitt B, Vranizan KM, Dreon DM, Wood PD. The effect of weight loss by dieting or exercise on resting metabolic rate in overweight men. Int J Obes 1990; 14: 327-34.

15. Verity LS, Ismail AH. Effects of exercise on cardiovascular disease risk in women with NIDDM. Diabetes Res Clin Pract 1989; 6: 27-35.

16. Maksimovic M, Ristic G, Maksimovic J, et al. Relationship between Physical Activity and some Parameters of Nutritional State in Adolescence. Srp Arh Celok Lek 2009; 137: 58-62.

17. Gordon L, Morrison EY, McGrowder DA, et al. Changes in clinical and metabolic parameters after exercise therapy in patients with type 2 diabetes. Arch Med Sci 2008; 4: 427-37.

18. Kamiński KA, Jasiewicz M, Knapp M, et al. Short period of exercise causes rapid increase of serum interleukin 6 with no effect on its soluble receptor. Arch Med Sci 2009; 5: 364-70.

19. Ziccardi P, Nappo F, Giugliano G, et al. Reduction of inflammatory cytokine concentrations and improvement of endothelial functions in obese women after weight loss over one year. Circulation 2002; 105: 804-9.

20. Malina RM. Adherence to physical activity from childhood to adulthood: a perspective from a tracking studies. Quest 2001; 53: 346-55.

21. National High Blood Pressure Education Program Working Group on High Blood Pressure in Children and Adolescents. The fourth report on the diagnosis, evaluation, and treatment of high blood pressure in children and adolescents. Pediatrics 2004; 114 (Suppl. $4^{\text {th }}$ Report): $555-76$. 